\title{
$\mathrm{Nb}$ 를 포함하는 불소산화물에서 구조적 뒤틀림에 따른 에너지 띠 간격의 변화
}

\author{
김현준 · 김승주* \\ 아주대학교 에너지시스템학부
}

(2007. 3. 22 접수)

\section{Variation of Band Gap Energy upon Structural Distortion for Nb-containing Oxyfluorides}

Hyun-Jun Kim and Seung-Joo Kim*

Division of Entrgy Systens Research, Ajot University: Sthwon 443-749. Korea

(Received March 22, 2007)

요 약. 국부적힌 결정구조와 에너지 미 간격 간 상관관계를 고찰하기 위하여 Nb를 포함하는 일련의 불소 산화물에 대하여 결성구조와 자외선-가시강선 학산 반사율 스펙토럽을 비교, 연구하였다. 이 실험에서 다룬

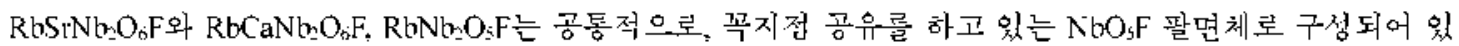

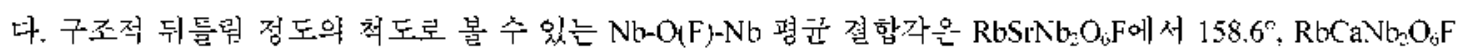
에서 $149.6^{\circ}$ 그러고 $\mathrm{RbNb}_{2} \mathrm{O}_{5} \mathrm{~F}$ 에서 $139.5^{\circ}$ 이다, 확산 반사율 스곈트럼으로부터 구한 에너지 미 간격은 $\mathrm{Nb}-\mathrm{O}(\mathrm{F}) \mathrm{Nb}$ 결합각이 감소할수록 증가하는 경항을 보였다. 즉 $\mathrm{RbSrNb}_{2} \mathrm{O}_{6} \mathrm{~F}_{1} \mathrm{RbCaNb}_{2} \mathrm{O}_{6} \mathrm{~F}, \mathrm{RbNb}_{2} \mathrm{O}_{5} \mathrm{~F}$ 각각의 화합물에 데 해 처 $3.48 \mathrm{eV}, 3.75 \mathrm{eV}, 4.03 \mathrm{eV}$ 의 값을 나타네었다. 이러한 실험적 결과는 $\mathrm{Nb}$ 를 포함하는 불소 산화물에서 국 부구조의 변화를 통해 미 간격을 약 $0.6 \mathrm{eV}$ 의 범위에서 조전할 수 있음을 의미한다.

주제어: 전이금속 불소산화물, 국부구조, 구조적 뒤틀람, 에너지 띠 간격, 페롭스카이트, 퐈이로클로어

ABSTRACT. A comparative study on crystal structures and UV-visible diffuse reflectance spectra for Nib-containing oxyfluorides was perfonned to probe the relationship between energy band gap and local structure. The oxyfluorides, $\mathrm{RbS}_{2}+\mathrm{Nb}_{2} \mathrm{O}_{2} \mathrm{~F}, \mathrm{RbCaNb}_{2} \mathrm{O}_{6} \mathrm{~F}$ and $\mathrm{RbNb}_{2} \mathrm{O}_{3} \mathrm{~F}$ are commonly composed of the comer-sharing $\mathrm{NbO}_{3} \mathrm{~F}$ octahedra as structural building units. The average $\mathrm{Nb}-\mathrm{O}(\mathrm{F})-\mathrm{Nb}$ bond angles, which can be a measure of the strucural distortion, are $158.6^{\circ}$ for $\mathrm{RbSrNb} \mathrm{O}_{2} \mathrm{~F}, 149.6^{\circ}$ for $\mathrm{RbCaNb}_{2} \mathrm{O}_{3} \mathrm{~F}$ and $139.5^{\circ}$ for $\mathrm{RbNb} \mathrm{O}_{5} \mathrm{~F}$. As the hond angle decreases, the band gap increases: $3.48 \mathrm{eV}$ for $\mathrm{RbSrNb}_{2} \mathrm{O}_{6} \mathrm{~F}, 3.75 \mathrm{eV}$ for $\mathrm{RbCaNb}_{2} \mathrm{O}_{2} \mathrm{~F}$ and $4.03 \mathrm{eV}$ for $\mathrm{Rb} \mathrm{Nb}_{2} \mathrm{O}_{3} \mathrm{~F}$. This experimental result implies that the band gap can be controlled with a range of $0.6 \mathrm{eV}$ through a variation of local stucure for the Nib-ontaining oxylluorides.

Keywords: Transition-metal Oxyfluoride, Local Structure, Stuctural Distortion, Band Gap, Peroyskite, Pyrochlore

\section{서 론}

물질의 전자구조는 광학적 성질과 전기전도도 및 화학반응성을 결정하는데 중요한 역할을 하며 그 물 질의 결정구조와 밀접한 관계를 가지고 있다. 물성 과 구조 간의 상관관계는 다양한 분야에서 유용하게
사웅될 수 있는냐 그 중 대표적인 예로서 반도케 물 질의 광촉매 작움에 관한 연구를 들 수 있다. Honda 와 Fuịishima에 의해 $\mathrm{TiO}_{2}$ 전극에 빛을 조사하면 광 산화환원 반응에 의해 물분해가 촉진된다는 사실이 발견된 이래, $\mathrm{TiO}_{2}$ 보다 향상된 에너지 변환 효율을 보이는 광혹매 물실 개발에 연구노력이 집중되고 있 
다. 1-3 광촉매 물질을 설계하는녜 우선 고려해야 하는 것은 홉수에너지를 결점짗는 에너지 띠 간격(band gap)야다. 에너지 띠 간격은 원자가 띠(valence band) 와 전도 띠(conduction band)의 위치와 나비에 영향 을 밚으며 이것은 결점 내의 화학결합 또는 결정구 조 변화를 통해 제어될 수 있다. 따라서 효율적인 광 촉매 물질을 개발하기 위해서는 고체 화합물의 전자 구조, 화학결합 및 결정 구조 간의 상호 연관섬을 야 해하는 것이 매우 중요하다.

지금까지 반도체 전이금속 화합물에처 에너지 띠 간격에 대한 많은 연구가 이루어졌고, 특히 비슷한 구조를 갖는 산화물에서 구성 원소와 에너지 띠 간 격 간의 관계는 잘 알려겨 있다. 예를 들면, Woodward 등은 여러 가지 $d^{\prime \prime}$ 전이금속을 포함하는 페롭스카야 트 화합물, $\mathrm{AMO}$ ( $\mathrm{A}=$ 알갈러 금속 또는 앎칼리 토금 속, $\mathrm{M}=\mathrm{Mo}, \mathrm{W}, \mathrm{Nb}, \mathrm{Ti}, \mathrm{Ta})$ 에 대한 연구에 서 유효 전 기흠성도가 가장 큰 $\mathrm{Mo}$ 를 포함하는 화합물이 유효 전기음성도가 가장 작은 $\mathrm{Ta}$ 를 포함하는 화합물보다 회대 $2 \mathrm{eV}$ 점도 각은 에너지 띠 간격을 갖는다고 보고 하였다. ${ }^{4}$

에너지 띠 간격을 결정하는 또 다론 중요한 요소 는 국부적인 결점구조이다. 전이금소 화합물에서 금 속이온 $\mathrm{M}$ 과 흠이온 $\mathrm{X}$ 의 결합각(M-X-M) 변화는 중 심금속의 $d$ 오비탈과 음이온의 $p$ 오비탈 간의 상호 작용을 변화시키며 결과적으로 에너지 띠 간격에 영 향을 줄 것으로 예상된다 나 그렇지반 국부구조에 따 른 에너지 띠 간격 변화에 대한 체계적인 비교 연구 는 충분히 이루어지지 않고 있다. 이 연구에서는 전 이금속 $\mathrm{Nb}$ 를 공통적으로 포함하고, 비슷한 조성을

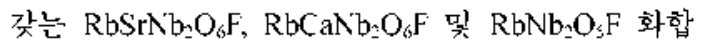
물에 대하여 국부 결점구조와 에너지 띠 간격 변화 를 비교함으로써 그늘 간 상관관계를 고찰했다.

\section{실 험}

이 실험에 서 다룬 화합물의 자세한 합성 방법은 눈 헌 $\cdots$ 에 보고되어 있다. $\mathrm{RbSrNb}_{2} \mathrm{O}_{6} \mathrm{~F}$ 와 $\mathrm{RbCaNb}_{2} \mathrm{O}_{6} \mathrm{~F}$ 시효 합성을 위해 전구물질로서 $\mathrm{SrNb}_{2} \mathrm{O}_{6}$ 와 $\mathrm{CaNb}_{2} \mathrm{O}_{6}$ 을 합성한 다음, 아르곤 기체가 채워진 잠감상자 안에 서 $\mathrm{RbF}$ 와 점량비로 혼합 후 금 튜브에 넣어 24시간 동안 열처리하었다. 열처리 온도는 $\mathrm{RbSrNb}_{2} \mathrm{O}_{6} \mathrm{~F}$ 와 $\mathrm{RbCaNb} \mathrm{O}_{i} \mathrm{~F}$ 에 대해 각각 $780^{\circ} \mathrm{C}$ 와 $840^{\circ} \mathrm{C}$ 었다. $\mathrm{Rb} b_{2} \mathrm{O}_{\mathrm{F}} \mathrm{F}$
시료는 $\mathrm{Nb}_{2} \mathrm{O}_{3}$ 와 $\mathrm{RbF}$ 을 정량비로 혼합하여 위와 마 찬가지로 금 튜브에 밀봉하여 $700^{\circ} \mathrm{C}$ 에서 24시간 동 안 가열하여 얻었다. 반응 후 생정물을 분쇄하여 $\mathrm{X}$-선 분말 회절기(Rigaku DMAX-2200PC)로 상을 확인하 였다.

결정 구조에 따튼 에너지 띠 간격을 측정하기 위 해 $\mathrm{BaSO}_{4}$ 를 표준 반사체로 하여 자외선-가시광선 분 광기(Shimadzu LV-2400 PC)로 200-800 nm 법위에서 확 산 반사 스펙트럼을 헐었다. 이렇게 헏은 반사울 녜 이터를 Kubelka-Munk 함수를 이용하여 흡광 지수로 변환하였다.

\section{결과 및 고참}

화합물 $\mathrm{RbSrNb} \mathrm{O}_{6} \mathrm{~F}, \mathrm{RbCaNb} \mathrm{O}_{6} \mathrm{~F}, \mathrm{RbVb}_{2} \mathrm{O}_{3} \mathrm{~F}$ 는 모 두 단일상으로 합정 되었으며 이들의 X-선 회절 패턴 을 Fig. (에 나타내었다. $\mathrm{RbSrNb}_{2} \mathrm{O}_{6} \mathrm{~F}$ 와 $\mathrm{RbCaNb}_{2} \mathrm{O}_{6} \mathrm{~F}$ 의 결정구조는 흥상 페롭스카이트 계에 속하며 자세 한 결정구조는 $\mathrm{X}$-선 회절과 중성자 회절 실험을 톰 해 밝혀겨 있다. ${ }^{2} \mathrm{RbSrNb}_{2} \mathrm{O}_{6} \mathrm{~F}$ 의 공간 군은 $P 4 / \mathrm{mmm}$ 이고 격자 상수는 $a=b=3.8503(1) \dot{A}, c=11.2841(3) \dot{A}$ 의 값을 나타낸다. $\mathrm{RbSrNb}_{2} \mathrm{O}_{6} \mathrm{~F}$ 구조는 $\mathrm{Nb}$ 원자가 5 개 의 산소와 1 개의 불소와 결합하여 $[\mathrm{NbO} F \mathrm{~F}]$ 퐐면체를 이룬다. 결정 축 $\mathrm{z}$ 방향으로 $\left[\mathrm{NbO}_{5} \mathrm{~F}\right]$ 날면체 두 개가 $\mathrm{F}$ 원자를 공유하면서 팔면체 이중 쯩을 이룬다. $\mathrm{Sr}$ 원자는 이들 팔면체 4 개의 줌심에 혐섬된 공간에 위 치한다. 따라서 미 구조단위를 폐롭스카이트 층,

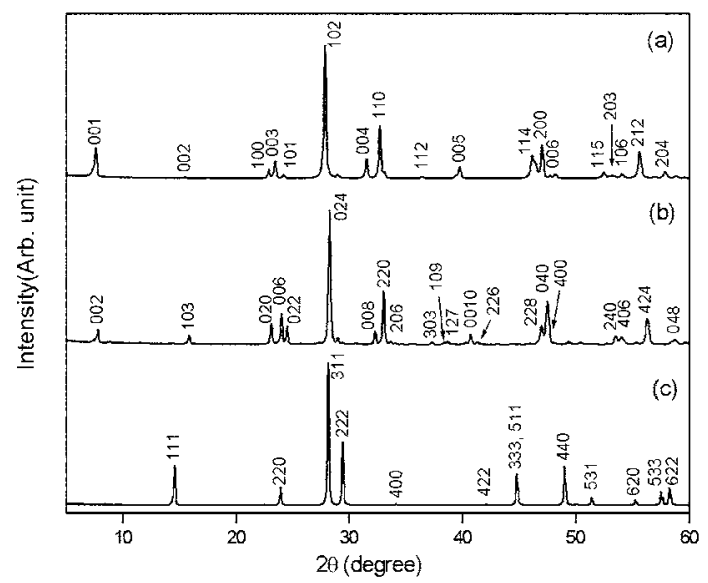

$F$ ig. 1. X-ray diffraction palterns for (a) $\mathrm{RbStNb}_{2} \mathrm{O}_{6} \mathrm{~F}$. (b) $\mathrm{RbCaNb}_{2} \mathrm{O}_{6} \mathrm{~F}$ and (c) $\mathrm{RbN}_{2} \mathrm{O}_{2} \mathrm{~F}$. 


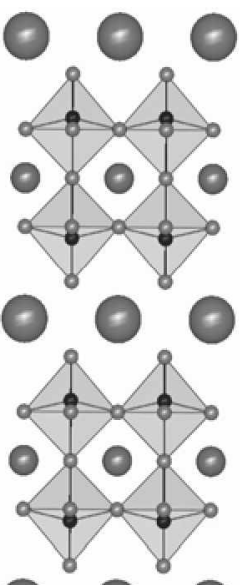

(a)

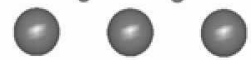

(b)

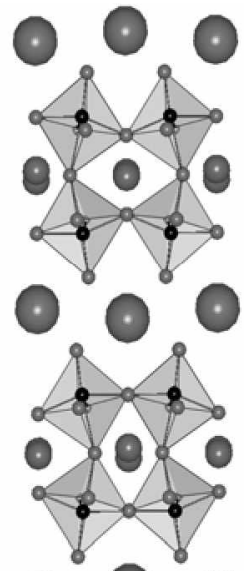

(
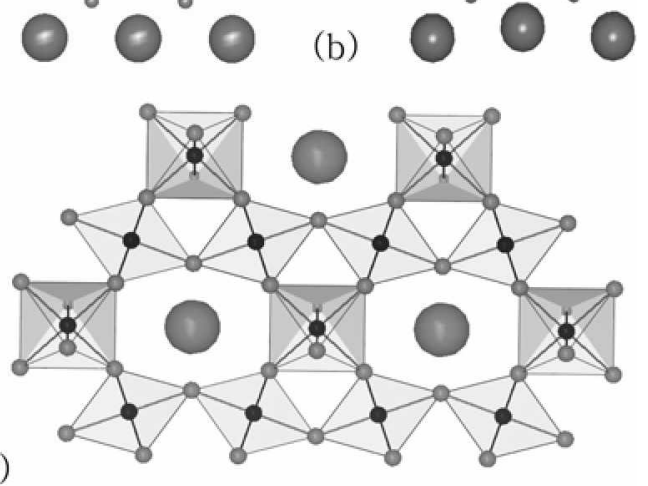

(c)

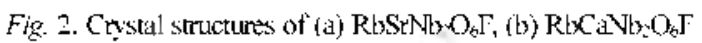
and (c) $\mathrm{RbN}, \mathrm{N}_{3} \mathrm{O}, \mathrm{F}$. $\mathrm{Rb}$ and $\mathrm{Sr}(\mathrm{Ca}$ ) atoms are represented by large spheres and small spheres, respectively. The octahedrally coordinated $\mathrm{Nb}$ atoms are represented by small filled spheres.

$\mathrm{Sr}\left(\mathrm{Nb}_{2} \mathrm{O}_{t} \mathrm{~F}\right)$-으로 표현할 수 있으며 이들 페롭스카이 트 구조단위는 $\mathrm{Rb}^{-}$이온을 차이에 두고 쯩층이 반북 된다(Fig. 2a). 이 구조에서 $\mathrm{Sr}$ 원자가 Ca 원자로 치

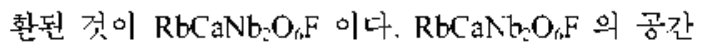
군은 $B m m b$ 이고 격자 상수는 $a=7,6058(5), b=7,6200(5)$, $c=22.023(1)$ 으로 보고되었다. ${ }^{8}$ 이 화합물에 서는 $\mathrm{Sr}$ 원 자에 비해 상대적으로 크기가 삭은 $\mathrm{Ca}$ 이 $\mathrm{NbO}$ : 퐐 면체들 사이에 위치하면서 구조적으로 불안정해지는 뎨, 이런 불안정성을 극복하기 위해서 $\mathrm{NbO}$ F 퐐면체
들이 서로 기울어겨 팔면체 둬틀람 (octahcdral tilting) 이 일어난다(Fig. $2 \mathrm{~b}$ ). 이러한 퐐면체 더틀람 현상은 결합각의 변화를 수반한다. 분헌에 있는 결정구조로

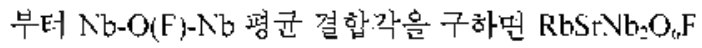
의 겅우에는 $158.6^{\circ}$ 이지만 $\mathrm{RbCaNb} \mathrm{O}_{4} \mathrm{~F}$ 화합물에서 는 구조적 뒤틀림으로 인해 그 값이 $149.6^{n}$ 로 감소했 음을 확인할 수 있다. 앞에서 기술한 $\mathrm{RbSr}_{2} \mathrm{Nb}_{2} \mathrm{O}_{6} \mathrm{~F}$ 또

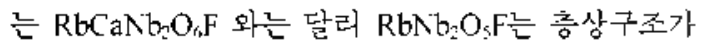
아닌 3차원 퐈이로클로러 구조로 결정화된다.?

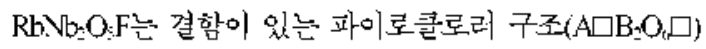
를 보이며 $\mathrm{F}$ 와 $\mathrm{O}$ 원자가 결정학적으로 동일한 자리 에 혼재되어 $\mathrm{NbO} \mathrm{F}$ 퐐먼체를 형성한다. 이 구조에서 도 페롭스카이트 구조에서와 마찬가지로 $\mathrm{NbO} s \mathrm{~F}$ 팔 면체들이 서로 꼭지접을 공유하면서 배열되어 있으 며 다만 $\mathrm{Nb}-\mathrm{O}(\mathrm{F}) \mathrm{-Nb}$ 결합 각 $\left(139.5^{\circ}\right)$ 이 상당히 삭다 는 짐이 다르다(Fig. 2c). Table 1에 세가.지 화합물에 대한 결정 정보를 정리하였다.

이 연구에서 다룬 세 가지 화합물은 흰색 분말 형 태미며 모두 자외선 영역의 빛을 홉수한다. 그 광학 적 홉수 스폑트럼을 $F \mathrm{ig}$. 3에 나타내었다. 이로부터 띠 간격 에너지 $\left(E_{g}\right)$ 를 결정하영 국부구조의 뒤틀람

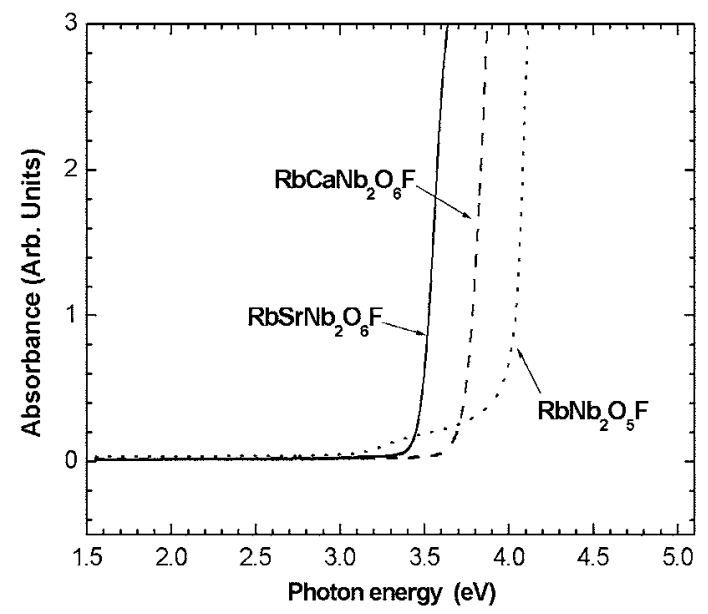

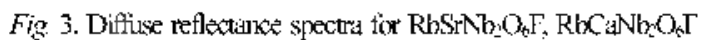
and $\mathrm{RbNb}_{2} \mathrm{O}$. F.

Table 1. Crystallographic data for compounds

\begin{tabular}{cccccc}
\hline \hline Compound & Symmetr: & $a / \mathrm{A}$ & $b / \mathrm{A}$ & $c / \mathrm{A}$ & ref. \\
\hline $\mathrm{RbSrNb} \mathrm{O}_{6} \mathrm{~F}$ & Tetragonal & $3.850311)$ & & $11.2841(3)$ & {$[7]$} \\
$\mathrm{RbCaNb}_{6} \mathrm{O}_{6} \mathrm{~F}$ & Orthorthombic & $7.608515)$ & $7.6200(5)$ & $22.02311)$ & {$[8]$} \\
$\mathrm{Rb}_{2} \mathrm{~b}_{2} \mathrm{O}_{3} \mathrm{~F}$ & Cubic & $10.49513)$ & & & {$[9]$} \\
\hline
\end{tabular}

2007. Iot. 91 . to 3 
Table 2. Local structure and optical band gap energ: $\left(E_{3}\right)$ of compounds

\begin{tabular}{|c|c|c|c|c|}
\hline Compound & Nb-O(F)-Nb angle (") & $\mathrm{Nb}-\mathrm{O}(\mathrm{F})-\mathrm{Nb}$ arerage angle (") & $\cos (180-\theta)$ & $\bar{E}(\mathrm{EV})$ \\
\hline \multirow{2}{*}{$\mathrm{RbSt} N b_{-} \mathrm{O}_{5} \mathrm{~T}$} & $180.0 \times 1$ & \multirow{2}{*}{158.6} & \multirow{2}{*}{0.93} & \multirow{2}{*}{3.48} \\
\hline & $153.2 \times 4$ & & & \\
\hline \multirow{5}{*}{$\mathrm{RbCaNb}_{2} \mathrm{O}_{5} \mathrm{~F}$} & $164.0 \times 1$ & \multirow{5}{*}{149.6} & \multirow{5}{*}{0.86} & \multirow{5}{*}{3.75} \\
\hline & $154.6 \times 1$ & & & \\
\hline & $148.0 \times 1$ & & & \\
\hline & $145.6 \times 1$ & & & \\
\hline & $135.6 \times 1$ & & & \\
\hline $\mathrm{RbNb}: \mathrm{O}_{4} \mathrm{~F}$ & $139.5 \times 6$ & 139.5 & 0.76 & 4.0 .3 \\
\hline
\end{tabular}

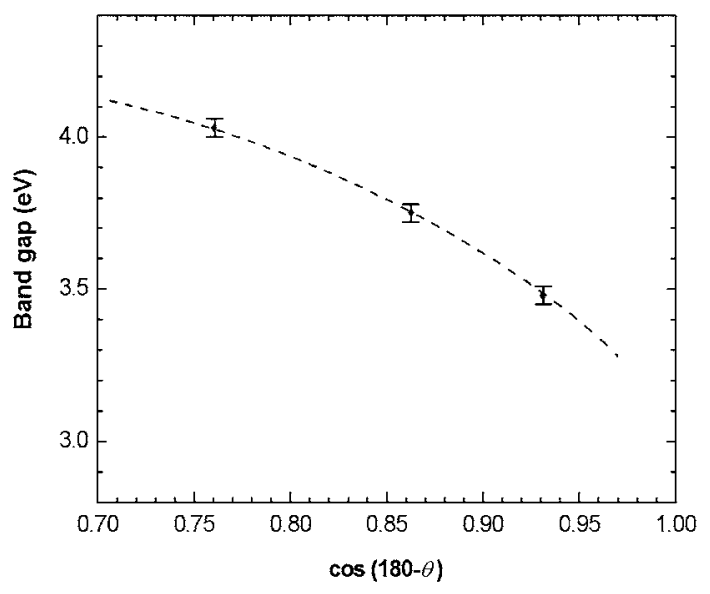

Fig. 4. Correlation between band gap energy and $\mathrm{Nb}-\mathrm{OMF}$ Nb tonding angle for oxyfluoride compounds.

점도와 함께 Table 2에 점러하였나. 국부구조의 뒤틀 람 정도는 $\mathrm{Nb}-\mathrm{O}(\mathrm{F})-\mathrm{Nb}$ 의 결합 각이 $180^{\circ}$ 로부터 멀어 지는 정도, 즉 $\cos (180-\theta)$ 으로 표현할 수 있으며 야 값이 1 에서 멀어짐에 따라 띠 간격 에너지가 증가하 는 경향을 보인다. 그 결과를 도시하면 Fig. 4와 같 다. 여기서 $\mathrm{Nb}-\mathrm{O}(\mathrm{F})-\mathrm{Nb}$ 결합각이 $180^{\circ}$ 에서 벌어질수 록, 즉 구조적 더틀림이 커질수록 띠 간격은 증가하 는녜, 증가하는 정도가 $\theta$ 값이 큰 부분으로 갈수록 점진적으로 감소한다. 이리한 결합각 증가에 따른 포 물선 형태의 띠 간격 변화 곡선은 $\mathrm{CaTiO}_{3}$ 에 대한 야 론적 계산 결과에서 예상되었는데 이 실험에서 다룬, $\mathrm{Nb}$ 를 포함하는 불소산화물에서도 동인한 경향이 나 타남을 확인할 수 있다. ${ }^{4}$

al 전자배치를 갖는 전이금속 화합물에서 에너지 띠 간격은 구성 원소의 선기음성도와 전도 띠 나비 에 의해 결정되는데 의 연구에서 다룬 세가지 화합 물의 기본구조는 공통적으로 $\mathrm{NbO} F$ 퐐면체로 이루
어지므로 선기음성도의 영향은 배제할 수 있다. 따 라서 관찰된 에너지 미 간격 변화는 순수하게 전도 띠 나비의 형향으로 생각할 수 있다. 전이금속 산화 물에 대한 최근의 에너지 띠 구조 변화 계산에 따르 면 구조의 뒤틀람이 커질수록 선도 띠가 비결합(nonbonding) 성 실에서 반결합(anti-bonding) 성실로 변화 하고 이로 인해 띠 나비가 갑소하여 결과적으로 띠 간격 에너지가 증가한다. ${ }^{411}$ 이레한 사질로부터 구조 적 뒤틀림이 가장 큰 $\mathrm{RbVb}_{2} \mathrm{O}_{5} \mathrm{~F}$ 에서 가장 작은 띠 나 비를 가진다고 할 수 있다.

결론적으로 $\mathrm{Nb}$ 를 포함하는 일련의 불소산화물에 서 국부 구조가 달라짐에 따라 $0.6 \mathrm{eV}$ 정도의 에너 지 띠 간격 변화가 수반됨을 알 수 있다. 이 연구에 서 다룬 화합물은 일반식 $\mathrm{RbA}_{1-\mathrm{X}} \mathrm{Nb}_{2} \mathrm{O}_{6-\mathrm{X}} \mathrm{F}$ 으로 표현할 수 있으며, $\mathrm{A}$ 자리에 크기가 다큰 원자 또는 결함을 위치시킴으로써 $\mathrm{Nb}-\mathrm{O}(\mathrm{F})-\mathrm{Nb}$ 결합각을 $140^{\circ}$ 에서 $160^{\circ}$ 법위 내에서 변화시킬 수 있었다. 이것은 결합각과 띠 간격 간의 상관성을 바탕으로 국부구조를 변화시 킴으로서 화합물의 띠 간격 제어가 가능함을 보여주 고 있다. 이러한 결과는 광촉매를 비롯한 다양한 기 능성 고체 화합물을 설계하는 녜 유욤할 것이다.

이 연구는 한국학술신흥재단의 지원에 의하여 연 구되었음(KRF-2004-003-C111).

\section{인 욤 문 헌}

1. Honda, K.; Fujishima A. Nature, 1972, $238,37$.

2. Domen, K.; Kudo, A.; Slunozaki, A.; Tanaka, A.; Marya, K.; Onishi, T. Chem. Commtm. 1986, 356.

3. Hur, S. G.; Kim, T. W.; Hwang, S. J.; Choy J. H. $J$. Photochem. Photobiol. A, 2006, 183, 176.

4. Eng. H. W.; Barnes, P. W.; Auer, B. M.; Woodward, P. 
M. J. Solid Siare chem., $2003,175,94$.

5. Mizoguchi, H.: Eng, H. W.; Woodward, P. M. Inorg. Chem, 2004, 43, 1667.

6. Harrison, H. W. The Elecronic Stricture and Properties of Solds : Freeman: San Fransco, LSA, 1980.

7. Choy, J. H.; Kim, J. Y.: Kim, S. J.: Soln, J. S.: Han, O.
H. Chem, Mater, 2001, 13,906.

8. Kim, S. J.; Kim H. J.; Yoo C. R.; Hong. K. P. Submitted to J. Solid State Chem.

9. Fourquet, J. L.; Jacoboni, C.; Pape, R. Hater: Res. Bull., $1973,8,393$.

10. Goodenough, J. B. J. Appl. Crist., 1997, 81, 5330. 